\title{
Study on risk factors of children's behavioral problems during prenatal and neonatal period
}

\author{
Min Zhang ${ }^{1 *}$, Tingting Huang ${ }^{2 \#}$, Yihuan YUE ${ }^{1}$, Jianshan Zheng ${ }^{1}, Z_{\text {hijian }}$ Chen $^{1}$ and Shunqin Wang ${ }^{*}$ \\ ${ }^{1}$ Xiamen Children's Hospital, China \\ ${ }^{2}$ Xiamen Xianyue Hospital, China \\ \#Equal contribution
}

\begin{abstract}
Objective: To understand the risk factors of children's behavioral problems during prenatal and neonatal period, so as to provide the scientific evidence for early prevention and intervention.

Methods: Totally 2257 children from 3 primary schools in Xiamen were surveyed by Achenbach Child Behavioral Checklist, and a multivariable logistic regression model was used to analyze the risk factors of children's behavioral problems.

Results: When children's gender, age, family socio-economic status and educational level of parents were considered, preterm birth $(O R=1.903, P=0.014)$, having history of being hospitalized during the neonatal period $(O R=1.783, P=0.006)$, maternal medication use during pregnancy $(O R=2.676, P<0.001)$ might be the main risk factors of children's behavioral problems during the prenatal and neonatal periods. Continuous breastfeeding for more than 6 months was the protective factor of children's behavioral problems $(O R=0.631, P=0.027)$. Maternal alcohol use in pregnancy might also increase the risk of children's behavioral problems $(O R$ $=2.591, P=0.058)$.
\end{abstract}

Conclusion: Early interference and monitoring of the psychological and developmental behaviors of the pretermog, longer duration of breastfeeding, reducing harmful factors exposure during pregnancy (such as alcohol, medicine) will play an important role to prevent and reduce children's behavioral problems.

\section{Introduction}

Children's behavioral problems not only directly affect their ability to learn and carry out daily life and social activities, but they may also have a negative impact on personality and behaviors when they are adults. In recent years, scholars have carried out a large number of related risk factors research in order to prevent and control children's behavior problems $[1,2]$. However, the current studies were focused on the risk factors that can be interfered with later in life such as family environment, parenting styles, and school education, etc. While systematically epidemiological studies on risk factors during prenatal and neonatal period were relatively few. This paper explores the risk factors of children's behavioral problems during prenatal and neonatal periods, so as to provide the scientific evidence for early prevention and intervention.

\section{Materials and methods}

\section{Subjects}

All students in grades 1 to 4 of three primary schools in Huli district of Xiamen City, Fujian Province were selected to participate in a questionnaire survey. A total of 2,443 questionnaires were handed out and 2,322 were returned (the respond rate was 95.04\%), of which the valid questionnaires was 2,257(the valid rate was 97.20\%). Among 2,257 students, 1,217(53.9\%) were boys and 1,040(46.1\%) were girls; the age distribution is: $215(9.5 \%)$ of 6 years old, $317(14.0 \%)$ of 7 years old, $547(24.2 \%)$ of 8 years old, $575(25.5 \%)$ of 9 years old, $372(16.5 \%)$ of 10 years, $231(10.2 \%)$ of 11 years.

\section{Methods}

Behavioral problems of the children were assessed by their parents using the Chinese version of the Child Behavior Checklist (CBCL). The $\mathrm{CBCL}$ is a questionnaire composed of 113 items rated on a three-step response scale ranging from 0 (absent) to 2 (very often present). The sum of individual item scores is converted to T-scores, in which higher scores indicate more severe problems. T-score $\geq 41$ was considered as children with behavioral problem and $\mathrm{T}$-score $<41$ was considered as normal children.

The possible risk factors of behavioral problems were collected through the General Status of Children Questionnaire which was self-designed. The contents of the questionnaire included: child and neonatal factors (gender, weight, height, birth weight, birth age and medical history, duration of breast-feeding, etc), parental factors (parent education background, parent's age when the child was born, alcohol and tobacco consumption, income, upbringing style, etc) and prenatal factors (X-ray exposure during pregnancy, maternal alcohol use and smoking in pregnancy, maternal medication use during pregnancy, delivery method, etc).

${ }^{\star}$ Correspondence to: Shunqin Wang, Xiamen Children's Hospital, Xiamen, Fujian, 361012, China, Tel: +86-592-5151918, +86-13720884041, E-mail: 21831168@qq.com

Key words: children, behavioral problem, prenatal and neonatal period, risk factors

Received: May 05, 2018; Accepted: May 23, 2018; Published: May 26, 2018 


\section{Statistical analysis}

The statistical analyses were performed with SPSS ver. 17.0. The Pearson $\chi^{2}$ test was used for single factor analysis and the Logistic regression analysis method was used for multi-factors analysis.

\section{Results}

\section{The detection rate of children's behavioral problems}

Of the 2,257 children, 287 were detected with behavioral problems. The detection rate was $12.70 \%$. For boys, the detection rate was $13.97 \%$, and the detection rate of girls was $11.25 \%(\chi 2=3.735, P=0.053)$. The detection rate of 6 years old was $12.09 \%, 7$ years old was $12.62 \%, 8$ years old was $14.07 \%$, 9 years old was $12.00 \%, 10$ years old was $12.03 \%, 11$ years old was $13.10 \%$, the differences of detection rates of various ages were not statistically significant $(\chi 2=1.444) \mathrm{P}=0.919)$.

\section{The single factor analysis}

The results of the Pearson $\chi 2$ test showed that the detection rates increased in the children with mother's education level $\leq$ primary school, abusive parenting style, preterm birth, having history of being hospitalized during the neonatal period, maternal medication use during pregnancy, maternal alcohol use in pregnancy $(P<0.05)$ (Table 1$)$.

\section{The multi-factors analysis}

The Logistic regression analysis was used to screen risk factors during prenatal and neonatal period of children's behavioral problems. Five independent variables (children's age, gender, family income, mother's education background, father's education background) were considered as control factors in the analysis model and 13 independent variables (Table 2) were analyzed by backward regression method with $P<0.05$ as variable inclusion criteria $P<0.10$ as variable exclusion criteria.

When children's gender, age, family's socio-economic status and educational level of parents were adjusted, preterm birth $(O R=1.903$, $P=0.014)$, having history of being hospitalized during the neonatal period $(O R=1.783, P=0.006)$, and maternal medication use during pregnancy $(O R=2.676, P<0.001)$ might be the main risk factors of children's behavioral problems during the prenatal and neonatal periods. Continuous breastfeeding for more than 6 months was the protective factor of children's behavioral problems $(O R=0.631, P=$ 0.027). Maternal alcohol use during pregnancy might also increase the risk of children's behavioral problems $(O R=2.591, P=0.058)$.

\section{Discussion}

The development of children's behavior problems is the result of the combination of many factors such as biology, family environment and society. Studies have shown that exposure to harmful factors during pregnancy and neonatal diseases are the most important risk factors for children's behavioral problems [3].

Premature infants are prone to brain damage because they are born early as the nervous system is not yet mature. Hutchinson conducted a survey on children with a gestational age $<28$ weeks when they were 8 years old and found that despite ongoing improvements

Table 1. The results of the single factor analysis.

\begin{tabular}{|c|c|c|c|c|c|c|c|c|c|}
\hline Variable & Category & Rate (\%) & $\chi^{2}$ & $P$ & Variable & Category & Rate (\%) & $\chi^{2}$ & $P$ \\
\hline \multirow{6}{*}{ Age(years) } & 6 & 12.1 & 1.400 & 0.924 & \multirow{6}{*}{ Family income (Yuan/month) } & $<5000$ & 17.2 & 7.550 & 0.110 \\
\hline & 7 & 12.6 & & & & $5000 \sim$ & 13.1 & & \\
\hline & 8 & 14.1 & & & & $10000 \sim$ & 11.0 & & \\
\hline & 9 & 12.0 & & & & $15000 \sim$ & 13.3 & & \\
\hline & 10 & 12.0 & & & & $\geq 20000$ & 10.4 & & \\
\hline & 11 & 13.1 & & & & & & & \\
\hline \multirow{2}{*}{ Gender } & Boy & 13.4 & 2.833 & 0.092 & Overweight / obesity of childc & Normal & 12.5 & 0.394 & 0.821 \\
\hline & girl & 11.1 & & & & Overweight & 11.2 & & \\
\hline \multirow{5}{*}{$\begin{array}{l}\text { Mother education } \\
\text { background }\end{array}$} & $\leq$ Primary school & 18.3 & 12.139 & 0.016 & & Obesity & 12.1 & & \\
\hline & Middle school & 12.3 & & & \multirow{5}{*}{ Mother education background } & $\leq$ Primary school & 19.8 & 8.269 & 0.082 \\
\hline & High school & 10.8 & & & & Middle school & 12.6 & & \\
\hline & Technical school & 12.3 & & & & High school & 13.4 & & \\
\hline & $\geq$ College/university & 11.3 & & & & Technical school & 10.5 & & \\
\hline \multirow{2}{*}{ Parents upbringing style a } & Education mainly & 11.5 & 20.980 & $<0.001$ & & $\geq$ College/university & 11.3 & & \\
\hline & Blame mainly & 24.0 & & & \multirow{2}{*}{ Age of maternity } & $<35$ years old & 12.4 & 0.723 & 0.395 \\
\hline \multirow{2}{*}{ Vaginal delivery } & Yes & 12.4 & 0.082 & 0.775 & & $\geq 35$ years old & 9.0 & & \\
\hline & No & 12.0 & & & \multirow{2}{*}{ Low birth weight } & No & 12.2 & 0.261 & 0.610 \\
\hline \multirow{2}{*}{ Preterm birth } & No & 11.5 & 15.570 & $<0.001$ & & Yes & 13.7 & & \\
\hline & Yes & 21.2 & & & \multirow{2}{*}{$\begin{array}{l}\text { History of being hospitalized during } \\
\text { the neonatal period }\end{array}$} & No & 11.7 & 6.490 & 0.011 \\
\hline \multirow{2}{*}{ Breast-feeding } & $<6$ months & 16.4 & 7.169 & 0.007 & & Yes & 17.3 & & \\
\hline & $\geq 6$ months & 11.8 & & & \multirow{2}{*}{ History of poor pregnancy of mother } & No & 11.9 & 2.589 & 0.108 \\
\hline \multirow{2}{*}{ Passive smoking $\mathrm{b}$} & No & 11.2 & 2.398 & 0.122 & & Yes & 15.4 & & \\
\hline & Yes & 13.4 & & & \multirow{2}{*}{$\begin{array}{l}\text { Maternal medication use during } \\
\text { pregnancyd }\end{array}$} & No & 12.0 & 10.779 & 0.001 \\
\hline \multirow{2}{*}{$\begin{array}{l}\text { Maternal smoking in } \\
\text { pregnancy }\end{array}$} & No & 12.8 & 0.394 & 0.530 & & Yes & 20.0 & & \\
\hline & Yes & 7.1 & & & \multirow{2}{*}{$\begin{array}{l}\text { Maternal alcohol use in } \\
\text { pregnancy }\end{array}$} & No & 12.4 & 14.564 & $<0.001$ \\
\hline \multirow{2}{*}{$\begin{array}{l}\text { X-ray exposure during } \\
\text { pregnancy }\end{array}$} & No & 12.2 & 0.350 & 0.554 & & Yes & 37.0 & & \\
\hline & Yes & 13.4 & & & & & & & \\
\hline
\end{tabular}

Note: a. No blaming the child or blaming the child $\leq 1$ times every week identified as "education mainly", while blaming the child $\geq 2$ times every week identified as "blame mainly". b. One or both parents smoke in the home. c. Identified according to Screening for overweight and obesity among school-age children and adolescents(WS/T586-2018).d. Including unprescribed or prescribed antiviral and antibiotic medicine. 
Table 2. The values in the Logistic regression model.

\begin{tabular}{|c|c|c|}
\hline Item & Variables & Values \\
\hline Dependent variable & Behavioral problems & No $=0$, Yes $=1$ \\
\hline \multirow{5}{*}{ Control variables } & Age(years) & $\begin{array}{l}6 \text { years }=1,7 \text { years }=2,8 \text { years }=3,9 \text { years }=4,10 \text { years }=5, \\
11 \text { years }=6\end{array}$ \\
\hline & Gender & Girl $=0$, Boy $=1$ \\
\hline & Mother education background & $\leq$ Primary school $=1$, Middle school $=2$, High school $=3$, Technical school $=4, \geq$ College $/$ university $=5$ \\
\hline & Father education background & $\leq$ Primary school $=1$, Middle school $=2$, High school $=3$, Technical school $=4, \geq$ College/ university $=5$ \\
\hline & Family income (Yuan/month) & $\begin{array}{l}5000 \text { Yuan } / \text { month }=1,5000 \text { Yuan } / \text { month } \sim=2,10000 \text { Yuan } / \text { month } \sim=3, \\
15000 \text { Yuan } / \text { month } \sim=4,20000 \text { Yuan } / \text { month } \sim=5\end{array}$ \\
\hline \multirow{14}{*}{ Independent variables } & Parents upbringing style & Education mainly $=0$, Blame mainly $=1$ \\
\hline & Overweight / obesity of child & Normal $=0$, Overweight $=1$, Obesity $=2$ \\
\hline & Age of maternity & $<35$ years old $=0, \geq 35$ years old $=1$ \\
\hline & Vaginal delivery & Yes $=0$, No $=1$ \\
\hline & Low birth weight & No $=0$, Yes $=1$ \\
\hline & Preterm birth & No $=0$, Yes $=1$ \\
\hline & $\begin{array}{l}\text { History of being hospitalized during the neonatal } \\
\text { period }\end{array}$ & No $=0$, Yes $=1$ \\
\hline & History of poor pregnancy of mother & No $=0$, Yes $=1$ \\
\hline & Passive smoking & No $=0$, Yes $=1$ \\
\hline & Breast-feeding & $<6$ months $=0, \geq 6$ months $=1$ \\
\hline & Maternal medication use during pregnancy & No $=0$, Yes $=1$ \\
\hline & Maternal smoking in pregnancy & No $=0$, Yes $=1$ \\
\hline & Maternal alcohol use in pregnancy & No $=0$, Yes $=1$ \\
\hline & $\mathrm{X}$-ray exposure during pregnancy & No $=0$, Yes $=1$ \\
\hline
\end{tabular}

Table 3. The results of the multiple factor analysis.

\begin{tabular}{|c|c|c|c|c|c|}
\hline Variables & $\boldsymbol{\beta}$ & SE & Wald $\chi^{2}$ & $P$ & $\operatorname{OR}(95 \% \mathrm{CI})$ \\
\hline Age & -0.048 & 0.057 & 0.693 & 0.405 & $0.953(0.852 \sim 1.067)$ \\
\hline Gender & 0.467 & 0.167 & 7.804 & 0.005 & $1.595(1.149 \sim 2.213)$ \\
\hline Mother education background & -0.351 & 0.110 & 10.197 & 0.001 & $0.704(0.568 \sim 0.873)$ \\
\hline Father education background & -0.048 & 0.101 & 0.230 & 0.631 & $0.953(0.783 \sim 1.074)$ \\
\hline Family income & -0.073 & 0.074 & 0.980 & 0.322 & $0.929(0.804 \sim 1.074)$ \\
\hline Parents upbringing style & 0.923 & 0.254 & 13.241 & $<0.001$ & $2.518(1.531 \sim 4.140)$ \\
\hline Preterm birth & 0.643 & 0.262 & 6.010 & 0.014 & $1.903(1.138 \sim 3.183)$ \\
\hline History of being hospitalized during the neonatal period & 0.579 & 0.211 & 7.550 & 0.006 & $1.783(1.180 \sim 2.694)$ \\
\hline Breast-feeding & 0.460 & 0.207 & 4.912 & 0.027 & $0.631(0.420 \sim 0.948)$ \\
\hline Maternalmedication use during pregnancy & 0.946 & 0.215 & 19.312 & $<0.001$ & $2.576(1.689 \sim 3.928)$ \\
\hline Maternal alcohol use in pregnancy & 0.952 & 0.502 & 3.607 & 0.058 & $2.592(0.970 \sim 6.927)$ \\
\hline
\end{tabular}

in the management of Premature infants, the rate of neurobehavioral impairment at school-age remains too high relative to controls [4]. Polic selected 253 6-12-year-olds children who were born late preterm (34 week $\sim 36$ week+6) and 131 full- term children and assessed their behavioral problems [5], and the results showed that children born late preterm had a greater risk for emotional and behavioral problems during childhood than their full-term born peers and they experienced serious health problems upon birth. In addition, Studies have shown that many neonatal diseases, such as neonatal asphyxia, intracranial hemorrhage, convulsions, and nuclear jaundice, can lead to brain damage in newborns, which can affect children's neurobehavioral development [3]. The neonatal health problems associated with prematurity present a negative impact on later child emotional and adapted behavior [6]. In this study, the results also revealed that children with preterm birth and having history of being hospitalized during the neonatal period were more likely to have behavioral problems. Therefore, for these children, it is necessary to plan the implementation of neuropsychological behavior development monitoring and early intervention to prevent and reduce long-term poor behavior problems.

The study by Grace found that breast feeding for $\geq 6$ months was positively associated with improved motor development outcomes at 10,14 and 17 years of age $(\beta=1.38, P=0.019)$ when adjusted for child's sex, maternal age, alcohol intake, family income, hypertensive status, gestational stress and mode of delivery [7]. Ye et al., found that breastfeeding with longer duration and increased intensity could promote better development in children [8]. Recently, a systematic review was conducted by Poton and the result showed that children breastfed for at least three to four months had fewer total behavior and conduct disorders in childhood [9]. In our study, continuous breastfeeding for more than 6 months was the protective factor of children's behavioral problems $(O R=0.631, P=0.027)$. It is suggested that prolonged breastfeeding time is a protective factor for children's behavior. Breast milk is rich in essential nutrients for infants and, which can promote the development of the brain and nerves of infants and young children. In addition, the exchange between mothers and infants during breastfeeding is conducive to the psychological development of infants and young children. Extending the duration of breastfeeding is beneficial to children's neurobehavioral development.

In our study, it also suggested that taking medication during pregnancy was one of the risk factors for children's behavioral problems. Excessive or inappropriate use of drugs during pregnancy will have adverse effects on fetal brain nerve damage and development, 
which will affect children's behavior in the future [10]. Populationbased epidemiological studies showed that alcohol consumption during pregnancy could hurt children's neurobehavioral development [11]. Although alcohol consumption during pregnancy of Chinese women in our survey is relatively light compared to that of western women, maternal alcohol consumption even at low levels was adversely related to child behavior [12]. This study also suggests that Maternal alcohol use in pregnancy might also contribute to increase the risk of children's behavioral problems $(O R=2.591, P=0.058)$.

Therefore, preterm birth, history of being hospitalized during the neonatal period, breast-feeding duration, maternal medication use during pregnancy, maternal alcohol consumption during pregnancy were the important risk factors for children's behavior problems during prenatal and neonatal periods. The result shows that early interference and monitoring of the psychological and developmental behaviors of the premature infants, longer duration of breastfeeding, reducing harmful factors exposure during pregnancy (such as alcohol, medicine) will play an important role to prevent and reduce children'i behavioral problems.

\section{Source(s) of support}

This study was supported by Project of Xiamen Science and Technology Bureau, Fujian Province in China (ID: 3502Z20164071).

\section{Conflict of interest}

The authors declare that they have no conflict of interest.

\section{References}

1. Mu LJ, Lu Y, Zhao J (2018) Study on correlation between family rearing environment and behavior development of 3-6 years old children. J Child Health Care 26: 63-66.
2. Liu T, Wang YR, Wu HS, Xu LQ, Qu LX, et al. (2017) Effects of Family Environment on the Behaviour of Children Left behind and Children Not Left Behind in Rural Areas. China Maternal and Children Health 4: 826-829.

3. Hu M, Jing J (2011) Research Progress on Influencing Factors of Behavioral Problems in reschoolers. Chin J Sch Health 32(4): 509-511.

4. Hutchinson EA, De Luca CR, Doyle LW, Roberts G, Anderson PJ; Victorian Infant Collaborative Study Group (2013) School-age outcomes of extremely preterm or extremely low birth weight children. Pediatrics 131: e1053-1061. [Crossref]

5. Polić B, Bubić A, Meštrović J, Markić J, Kovačević T, et al. (2017) Emotional and behavioral outcomes and quality of life in school-age children born as late preterm: retrospective cohort study. Croat Med J 58: 332-341. [Crossref]

6. Cassiano RG, Gaspardo CM, Linhares MB (2016) Prematurity, neonatal health status, and later child behavioral/emotional problems: a systematic review. Infant Ment Health $J$ 37: 274-288. [Crossref]

7. Grace T, Oddy W, Bulsara M, Hands B (2017) Breastfeeding and motor development A longitudinal cohort study. Hum Mov Sci 51: 9-16. [Crossref]

8. Ye AX, Tao XY, Yan SQ, Zuo AZ, Pan WJ, et al. (2017) [Effect of breastfeeding on the behavioral development of infants and children: a birth cohort study in Ma'anshan. Zhonghua Yu Fang Yi Xue Za Zhi 51: 807-813. [Crossref]

9. Poton WL, Soares ALG, Oliveira RA, Gonçalves H (2008) Breastfeeding and behavior disorders among children and adolescents: a systematic review. Rev Saude Publica 52: 9. [Crossref]

10. Meng CJ (2014) Effects of medication on fetal brain nerve development during pregnancy. Chinese J Pract Nerv Dis 17: 82-83.

11. Polanska K, Jurewicz J, Hanke W (2015) Smoking and alcohol drinking during pregnancy as the risk factors for poor child neurodevelopment - A review of epidemiological studies. Int J Occup Med Environ Health 28: 419-443. [Crossref]

12. Gao H, Zhao S, Wang YL (2011) Survey on maternal self-reported alcohol use and childhood behavior associated with prenatal alcohol exposure. J Child Health Care 19: 423-425. [Crossref]

Copyright: (C2018 Zhang M. This is an open-access article distributed under the terms of the Creative Commons Attribution License, which permits unrestricted use, distribution, and reproduction in any medium, provided the original author and source are credited. 